\title{
Penatalaksanaan Gangguan Rasa Nyaman Nyeri dengan Teknik Relaksasi di Ruang Topas RSU dr. Slamet Garut
}

\author{
Theresia Eriyani ${ }^{1}$, Iwan Shalahuddin ${ }^{2}$
}

\begin{abstract}
Abstrak
Pelaksanaan teknik relaksasi oleh perawat kurang diaplikasikan terhadap pasien yang mengalami gangguan rasa nyaman nyeri. Hal ini disebabkan oleh beberapa faktor seperti : Pendidikan, Jenis kelamin dan jadwal dinas. Tujuan dalam penelitian ini adalah untuk mengetahui Penatalaksanaan gangguan rasa nyaman nyeri dengan teknik relaksasi pada perawat di ruang Topas RSU dr. Slamet Garut. Metode dalam penelitian ini menggunakan metode penelitian deskriftif. Sebagai responden dalam penelitian ini adalah seluruh perawat yang bekerja di ruang Topas RSU dr. Slamet Garut. Data yang diperoleh diolah dan dianalisis dengan uji univariat. Instrumen yang digunakan dalam penelitian ini berupa SOP (Standar Operasional Prosedur) untuk mengobservasi teknik relaksasi oleh perawat terhadap pasien, dari hasil penelitian diperoleh distribusi frekuensi perawat berdasarkan pelaksanaaan teknik relaksasi,pendidikan,jadwal dinas dan jenis kelamin. Adapun pelaksanaan teknik relaksasi oleh perawat di Ruang Topas RSU dr. Slamet Garut perawat yang melaksanakan teknik relaksasi sebanyak 8 orang $(50 \%)$ dan yang tidak melaksanakan sebanyak 8 orang atau $50 \%$.
\end{abstract}

Kata kunci : Penatalaksanaan, rasa nyaman nyeri, relaksasi

\begin{abstract}
The implementation of relaxation techniques by nurses is less applied to patients who experience pain relief. This is caused by several factors such as: Education, Gender and service schedule. The purpose of this study was to find out the management of pain relief disorders with relaxation techniques in nurses in the Topas room of RSU Dr. Slamet Garut. The method in this study uses descriptive research methods. As respondents in this study were all nurses working in the Topas room of RSU Dr. Slamet Garut. The data obtained was processed and analyzed by univariate tests. The instrument used in this study is an SOP (Standard Operating Procedure) to observe relaxation techniques by nurses on patients, from the results of the study obtained nurse frequency distribution based on the implementation of relaxation techniques, education, service schedules and gender. The implementation of relaxation techniques by nurses in the topas room of RSU Dr. Slamet Garut nurses who carry out relaxation techniques as many as 8 people or $50 \%$ and those who do not implement as many as 8 people or $50 \%$.
\end{abstract}

Keywords: Feeling comfortable pain, management, relaxation

\section{PENDAHULUAN}

Globalisasi telah memberi dampak positif bagi setiap profesi kesehatan untuk selalu berupaya meningkatkan kinerja profesionalnya dalam kontribusi pada berbagai kebutuhan kesehatan masyarakat. Hal ini sejalan dengan semakin meningkatnya tuntutan masyarakat akan kualitas pelayanan kesehatan. Peningkatan tuntutan ini akibat dari meningkatnya jumlah konsumen yang terdidik, sehingga mampu memilih jenis dan kualitas pelayanan yang diinginkan (DR.Ratna sitorus, 2006). 
Tenaga profesional kesehatan termasuk didalamnya tenaga keperawatan telah menetapkan arah perkembangan keprofesionalannya, antara lain melalui sistem pendidikan tinggi keperawatan yang telah menghasilkan berbagai jenjang pendidikan keperawatan, yaitu ners generalis dan ners spesialis di berbagai bidang keilmuan keperawatan. Arah perkembangan ini sejalan dengan perkembangan ilmu pengetahuan,teknologi kesehatan dan keperawatan yang bertujuan untuk mengantisipasi berbagai perubahan, tantangan, dan peluang di era global ini (DR.Ratna sitorus, 2006).

Pelayanan keperawatan (Nursing Service) mencakup bidang yang sangat luas. Pelayanan keperawatan merupakan suatau upaya untuk membantu individu sakit maupun sehat, dari lahir sampai meninggal dalam bentuk peningkatan pengetahuan dan kemampuan yang dimiliki sehingga individu tersubut dapat melakukan kegiatan sehari-hari secara mandiri dan optimal (H.Zaidin Ali, 2001). Keperawatan adalah pelayanan profesional yang merupakan bagian dari pelayanan kesehatan, berdasarkan ilmu dan kiat keperawatan, berbentuk pelayanan biopsiko-sosio-spiritual yag komprehensif dan ditujukan kepada individu, kelompok, dan masyarakat baik sakit maupun sehat (A.Aziz Alimul H, 2008).

Menurut Internasional Council of Nursing (1965) Perawat adalah seseorang yang telah menyelesaikan program pendidikan keperawatan, berwenang di negara bersangkutan untuk memberikan pelayanan, dan bertanggung jawab dalam peningkatan kesehatan, pencegahan penyakit serta pelayanan terhadap pasien (H.Zaidin Ali, 2001). Peran perawat yaitu sebagai pelaksana pelayanan keperawatan, pengelola pelayanan keperawatan dan institusi pendidikan, pendidik dalam keperawatan dan peneliti pengembang keperawatan. Peran terapeutik perawat yaitu kegiatan yang ditujukan langsung pada pencegahan dan pengobatan penyakit.

Proses keperawatan merupakan cara sistematis yang dilakukan perawat bersama pasien dalam menentukan kebutuhan asuhan keperawatan dengan melakukan pengkajian, penentuan diagnosis, perencanaan tindakan, pelaksanaan tindakan, serta pengevaluasian hasil asuhan yang telah diberikan dengan berfokus pada pasien dan berorientasi pada tujuan. Setiap tahapan saling bergantung dan berhubungan (Alimul, 2008).

Nyeri merupakan kondisi berupa perasaan tidak menyenangkan bersifat sangat subjektif karena perasaan nyeri berbeda pada setiap orang dalam hal skala atau tingkatannnya, dan hanya orang tersebutlah yang dapat menjelaskan atau mengevaluasi rasa nyeri yang dialaminya (Alimul, 2008). Nyeri merupakan pengalaman sensori dan emosional yang tidak menyenangkan akibat dari kerusakan 
jaringan yang aktual atau potensial (Smeltzer dan Bare, 2002). Dengan adanya gangguan rasa nyaman nyeri, maka nyeri mengakibatkan kebutuhan dasar yang lain menjadi terganggu seperti pola aktivitas sehari-hari, nafsu makan dan kebutuhan istirahat tidur (Smeltzer dan Bare, 2002).

\section{Penatalaksanaan}

(tindakan)

keperawa-tan gangguan nyaman nyeri diantaranya ada yang bersifat farmakologi dan ada juga yang bersifat non farmakologi. Yang bersifat farmakologi yaitu pemberian obat analgesik, dilakukan guna mengganggu atau memblok transmisi stimulus agar terjadi perubahan persepsi dengan cara mengurangi kortikal terhadap nyeri. Dan yang bersifat non farmakologi yaitu dengan mengurangi faktor yang dapat menambah nyeri, misal ketidakpercayaan, kesalahpahaman, ketakutan, kelelahan, dan kebosanan. Memodifikasi stimulus nyeri menggunakan teknik seperti: teknik pengalihan, memodifikasi telivisi, berbincang-bincang dengan orang lain, mendengarkan musik dan teknik relaksasi (Alimul, 2008).

Menurut Smeltzer dan Bare (2002), teknik relaksasi dipercaya dapat menurunkan nyeri dengan merilekskan ketegangan otot yang menunjang nyeri. Relaksasi merupakan kebebasan mental dan fisik dari ketegangan dan stress, karena dapat mengubah persepsi kognitif dan motivasi afektif pasien. Teknik relaksasi membuat pasien dapat mengontrol diri saat terjadi rasa tidak nyaman atau nyeri, stress fisik dan emosi (Potter \& Perry, 2005). Teknik relaksasi merupakan metode yang dapat dilakukan terutama pada pasien yang mengalami nyeri, merupakan latihan pernafasan yang menurunkan konsumsi oksigen, frekuensi pernafasan, frekuensi jantung dan ketegangan otot yang menghentikan siklus nyeri, ansietas dan ketegangan otot. Teknik relaksasi perlu diajarkan bebarapa kali agar mencapai hasil optimal dan perlunya instruksi menggunakan teknik relaksasi untuk menurunkan/mencegah nyeri meningkat.

$$
\text { Berdasarkan penelitian Ikhsan }
$$
(2010), tentang Peran tekhnik relaksasi terhadap gangguan rasa nyaman nyeri di RS DR. M. Yunus Bengkulu, dari hasil penelitian tersebut menyatakan bahwa "Pelaksanaan tehnik relaksasi terhadap tngkat nyeri pada pasien pasca operasi di RSUD Dr. M Yunus Bengkulu Tahun 2010 sangat berpengaruh sekali hingga mencapai $50 \%$. Hal tersebut sesuai teori yang mengatakan ada beberapa non farma kologi untuk mengurangi nyeri yaitu salah satunya dengan tekhnik relaksasi nafas dalam. Tehnik relaksasi ini merupakan tehnik yang efektif mengontrol ketidaknyamanan (Smeltzer dan Bare, 2002).

Ruang Topas RSU dr. Slamet merupakan ruang khusus Bedah untuk lakilaki yang didalamnya mencakup pasien Post Operasi diantaranya Post Operasi 
BPH, Fraktur, Hernia dan lain-lain. Post Operasi tersebut mengakibatkan terputus kontinuitas jaringan yang diantaranya bisa menimbulkan gangguan rasa nyaman nyeri. Penatalaksanaan dari gangguan rasa nyaman nyeri diantaranya yaitu dengan cara Tekhnik relaksasi nafas dalam. Berdasarkan studi pendahuluan dengan wawancara pada 10 orang perawat di Ruang Topas, semua perawat mengetahui Penatalaksanaan gangguan rasa nyaman nyeri dengan teknik relaksasi, 4 perawat diantaranya mengetahui dan melaksanakan penatalaksanaan gangguan rasa nyaman nyeri dengan teknik relaksasi dengan tidak memperhatikan SOP dan 6 diantaranya mengetahui tetapi tidak melaksanakan penatalaksanaan gangguan rasa nyaman nyeri dengan tekhnik relaksasi.

\section{METODE PENELITIAN}

Desain penelitian yang digunakan adalah deskroptif dengan pendekatan cross sectional. Arikunto (2010) menyatakan penelitian deskriptif bertujuan mengetahui gambaran penatalaksanaan gangguan rasa nyaman nyeri dengan tekhnik relaksasi pada perawat di ruang Topas RSU dr. Slamet Garut. Rancangan cross sectional merupakan rancangan penelitian yang pengukuran atau pengamatanya dilakukan secara simultan pada satu saat atau sekali waktu (Hidayat, 2007).

Variabel dalam penelitian ini adalah gambaran pengetahuan perawat dalam penatalaksanaan gangguan rasa nyaman nyeri dengan teknik relaksasi di ruang Topas RSU dr. Slamet Garut. Pengetahuan merupakan hasil dari apa yang diketahui seseorang dan ini terjadi setelah orang tersebut melakukan pengindraan terhadap objek tertentu. Pengetahuan atau kognitif merupakan dominant yang sangat penting terbentuknya tindakan seseorang, sebagian pengetahuan manusia diperoleh melalui mata dan telinga (Notoatmodjo, 2010).

Populasi penelitian adalah seluruh subjek atau objek dengan karakteristik tertentu yang akan diteliti (Aziz Alimul, 2003). Yang menjadi populasi pada penelitian ini adalah seluruh perawat yang bekerja di ruang Topas RSU dr. Slamet Garut. Jadi jumlah populasi yang diteliti mencakup seluruh perawat yang bekerja di ruang Topas RSU dr. Slamet Garut. Yaitu berjumlah 16 orang. Pengambilan sampel penelitian adalah sebagian dari jumlah dan karakteristik yang dimiliki oleh populasi tersebut (Setiadi, 2007). Dalam penelitian ini peneliti menggunakan teknik sampling jenuh yakni cara pengambilan sampel dengan mengambil anggota populasi semua menjadi sampel. Cara ini dilakukan karena populasinya kecil dan sampelnya kurang dari 30 orang. Sampel yang akan dijadikan responden dalam penelitian ini berjumlah 16 orang mencakup seluruh perawat yang bekerja di ruang topas RSU dr. Slamet Garut. 
Pengumpulan data berupa observasi. Metode observasi yang digunakan peneliti adalah bentuk observasi atau pengamatan terlibat (Notoatmodjo, 2005). Untuk variabel penatalaksanaan digunakan SOP (Standar Operasional Prosedur) maka Instrumen yang digunakan dalam pengumpulan data pada penelitian ini adalah check list yaitu suatu daftar untuk men"cek" beberapa gejala dari sasaran penelitian. Peneliti tinggal memberikan tanda check $(\sqrt{ })$ pada daftar tersebut yang menunjukkan adanya gejala atau ciri dari sasaran peneliti, apabila perawat melaksanakan diberi tanda check $(\sqrt{ })$ pada kolom Ya, dan apabila perawat tidak melaksanakan diberi tanda check $(\sqrt{ })$ pada kolom Tidak (Notoatmodjo, 2010). Untuk variabel pendidikan responden cukup men check list $(\sqrt{ })$ di lembar data demografi. Untuk variabel Jadwal dines responden cukup men check list $(\sqrt{ })$ di lembar data demografi. Untuk variabel Jenis kelamin responden cukup men check list $(\sqrt{ })$ di lembar data demografi.

\section{HASIL DAN PEMBAHASAN}

\section{Hasil Penelitian}

Penelitian tentang penatalaksanaan gangguan rasa nyaman nyeri dengan teknik relaksasi pada perawat di ruang topas RSU dr. Slamet Garut, dilakukan dengan mengobservasi perawat menggunakan format SOP. Responden dalam penelitian ini adalah perawat yang berjumlah 16 orang,dari 16 perawat didapatkan data demografi dan data penatalaksanaan gangguan rasa nyaman nyeri dengan teknik relaksasi, yang dapat dilihat di bawah ini :

Tabel 1. Distribusi Frekuensi Perawat Berdasarkan Pelaksanaan Teknik Relaksasi di Ruang Topas RSU dr. Slamet Garut No Pelaksanaan Frekuensi Persentase

\begin{tabular}{llcc} 
& & $(\mathbf{\%})$ \\
\hline 1 & Dilaksanakan & 8 & 50 \\
2 & $\begin{array}{l}\text { Tidak } \\
\text { dilaksanakan }\end{array}$ & 8 & 50 \\
\hline & Jumlah & $\mathbf{1 6}$ & $\mathbf{1 0 0}$ \\
\hline
\end{tabular}

Berdasarkan tabel 1 dapat diketahui bahwa melaksanakan $\geq$ median perawat dianggap pelaksanaan teknik relaksasi dilaksanakan sesuai dengan SOP yang berjumlah 8 orang dengan presentase $50 \%$, sedangkan yang tidak melaksanakn < median dianggap pelaksanaan teknik relaksasi tidak dilaksanakan dengan jumla perawat 8 orang dengan presentase $50 \%$.

Tabel 2. Distribusi Frekuensi Perawat Berdasarkan Pendidikan di Ruang Topas RSU dr. Slamet Garut

\begin{tabular}{clcc}
\hline No & Pendidikan & Frekuensi & Persentase (\%) \\
\hline 1 & Diploma & 10 & 62.5 \\
2 & Sarjana & 6 & 37,5 \\
\hline & Jumlah & $\mathbf{1 6}$ & $\mathbf{1 0 0}$ \\
\hline
\end{tabular}

Berdasarkan tabel 2, dapat diketahui bahwa pendidikan perawat lebih banyak berpendidikan diploma daripada sarjana sebanyak 62,5 \%, sedangkan yang pendidikan sarjana sebanyak $37,5 \%$.

Tabel 3. Distribusi Frekuensi Perawat Berdasarkan Jadwal Dinas di Ruang Topas RSU dr. Slamet Garut

\begin{tabular}{clcc}
\hline No & Jadwal Dinas & Frekuensi & Persentase (\%) \\
\hline 1 & Pagi & 7 & 43,75 \\
2 & Siang & 5 & 31,25
\end{tabular}




\begin{tabular}{|c|c|c|c|}
\hline 3 & Malam & 4 & 25 \\
\hline & Jumlah & 16 & 100 \\
\hline
\end{tabular}

diketahui jadwal dinas perawat lebih

banyak dinas pagi yaitu sebanyak 7 orang

$(43,75 \%)$ dan paling sedikit yaitu jadwal

dinas malam yaitu sebanyak 3 orang atau

$18,75 \%$.

Tabel 4. Distribusi Frekuensi Perawat Berdasarkan Jenis Kelamin di Ruang Topas RSU dr. Slamet Garut

\begin{tabular}{clcc}
\hline No & Jenis Kelamin & Frekuensi & Persentase (\%) \\
\hline 1 & Laki-laki & 14 & 87,5 \\
2 & Perempuan & 2 & 12,5 \\
& Jumlah & $\mathbf{1 6}$ & $\mathbf{1 0 0}$ \\
\hline
\end{tabular}

Berdasarkan tabel 4, dapat diketahui bahwa perawat di ruang topas lebih banyak perawat laki-laki dari pada perempuan yaitu sebanyak 14 orang atau 87,5\% sedangkan perempuan sebanyak 2 orang atau $12,5 \%$.

Tabel 5. Distribusi Frekuensi Perawat dalam Pelaksanaan Teknik Relaksasi Berdasarkan Pendidikan di Ruang Topas RSU dr. Slamet Garut

\begin{tabular}{ccccccc}
\hline \multirow{2}{*}{ No } & \multirow{2}{*}{ Pendidikan } & \multicolumn{3}{c}{ Pelaksanaan } & \multirow{2}{*}{ Jumlah } \\
\cline { 3 - 6 } & & \multicolumn{2}{c}{ Ya } & \multicolumn{2}{c}{ Tidak } & Jumlan \\
\cline { 3 - 6 } & D & \% & F & \% & \\
\hline 1 & Diploma & 4 & 40 & 6 & 60 & 10 \\
2 & Sarjana & 4 & 66,5 & 2 & 33,5 & 6 \\
\hline \multirow{2}{*}{} & Jumlah & & $\mathbf{8}$ & & $\mathbf{8}$ & $\mathbf{1 6}$ \\
\hline
\end{tabular}

Berdasarkan tabel 5, dapat diketahui bahwa perawat yang pendidikan diploma yang melaksanakan teknik relaksasi berjumlah 4 orang atau $40 \%$ dan yang tidak melaksanakan teknik relaksasi sebanyak 6 orang atau 60\%. Sedangkan yang pendidikan sarjana yang melaksanakan teknik relaksasi berjumlah 4 orang atau $66,5 \%$, dan yang tidak melaksanakan teknik relaksasi sebanyak 2 orang atau $33,5 \%$.

Tabel 6. Distribusi Frekuensi Perawat dalam Pelaksanaan Teknik Relaksasi Berdasarkan Jadwal Dinas di Ruang Topas RSU Dr. Slamet Garut

\begin{tabular}{clccccc}
\hline & & \multicolumn{4}{c}{ Pelaksanaan } & \\
\cline { 3 - 6 } No & Jadwal & \multicolumn{3}{c}{ Ya } & \multicolumn{3}{c}{ Tidak } & Jumlah \\
\cline { 3 - 6 } & Dinas & F & \% & F & \% & \\
\hline 1 & Pagi & 7 & 100 & - & - & 7 \\
2 & Siang & 1 & 20 & 4 & 80 & 5 \\
3 & Malam & - & - & 4 & 100 & 4 \\
\hline & Jumlah & $\mathbf{8}$ & & $\mathbf{8}$ & & $\mathbf{1 6}$ \\
\hline
\end{tabular}

Berdasarkan tabel 6, diketahui bahwa jadwal dinas perawat mempengaruhi pelaksanaan teknik relaksasi,terbukti dari jadwal dinas pagi,siang dan malam dinas pagi yang paling banyak melaksanakan teknik relaksasi yaitu sebanyak 7 orang atau $100 \%$ dan tidak ada yang tidak melaksanakan teknik relaksasi. Sedangkan yang banyak tidak melaksanakan teknik relaksasi yaitu dinas malam sebanyak 4 orang atau $100 \%$ tdak melaksanakan. Dan dinas siang yang tidak melaksanakan teknik relaksasi sebanyak 4 orang atau 80 $\%$ dan yang melaksanakan teknik relaksasi sebanyak 1 orang atau $20 \%$.

Tabel 7. Distribusi Frekuensi Perawat dalam Pelaksanaan Teknik Relaksasi Berdasarkan Jenis Kelamin di Ruang Topas RSU Dr. Slamet Garut

\begin{tabular}{ccccccc}
\hline & & \multicolumn{3}{c}{ Pelaksanaan } & \\
\cline { 3 - 6 } No & Jenis & \multicolumn{2}{c}{ Ya } & \multicolumn{2}{c}{ Tidak } & Jumlah \\
\cline { 3 - 6 } & Kelamin & F & \% & F & \% & \\
\hline 1 & Laki-laki & 7 & 50 & 7 & 50 & 14 \\
2 & Perempuan & 1 & 50 & 1 & 50 & 2 \\
\hline & Jumlah & $\mathbf{8}$ & & $\mathbf{8}$ & & $\mathbf{1 6}$ \\
\hline
\end{tabular}


Berdasarkan tabel 7, dapat diketahui bahwa perawat laki-laki lebih banyak dari pada perawat perempuan berjumlah 14 orang dan perawat perempuan hanya 2 orang. Dari 14 orang perawat laki-laki sebanyak 7 orang atau 50\% yang melaksanakan teknik relaksasi dan 7 orang atau $50 \%$ yang tidak melaksanakan teknik relaksasi. Sedangkan perawat perempuan dari 2 orang perawat 1 orang melaksanakan teknik relaksasi atau $50 \%$ dan 1 orang tidak melaksanakan teknik relaksasi (50\%).

\section{Pembahasan}

Berdasarkan hasil distribusi frekuensi pelaksanaan teknik relaksasi perawat yang melaksanakan teknik relaksasi sebanyak 8 orang atau $50 \%$ dan perawat yang tidak melaksanakan teknik relaksasi sebanyak 8 orang atau $50 \%$ sehingga perawat yang melaksanakan dan tidak melaksanakan teknik relaksasi seimbang yaitu 50\%. Hal ini terjadi dikarenakan beberapa factor baik itu pendidikan, jadwal dinas,dan jenis kelamin. Sejalan dengan Zees, R. F. (2012), teknik relaksasi dipercaya dapat menurunkan nyeri dengan merilekskan ketegangan otot yang menunjang nyeri. Relaksasi merupakan kebebasan mental dan fisik dari ketegangan dan stress, karena dapat mengubah persepsi kognitif dan motivasi afektif pasien. Teknik relaksasi membuat pasien dapat mengontrol diri ketika terjadi rasa tidak nyaman atau nyeri, stress fisik dan emosi pada nyeri (Pinandita, Purwanti \& Utoyo, B,2012).

Hasil penelitian ini menunjukan bahwa perawat yang melaksanakan teknik relaksasi seimbang dengan perawat yang tidak melaksanakan teknik relaksasi, artinya pasien yang pre maupun post operasi ada yang tidak mendapatkan teknik relaksasi. Hal ini kurang baik karena akan mengakibatkan nyeri yang sangat berat,dan timbulnya stress terhadap pasien. Upaya yang harus di perhatikan perawat bahwa pelaksanaan teknik relaksasi pada pasien pre maupun post operasi sangatlah penting dan harus diperhatikan karena teknik relaksasi akan mengurangi tingkat nyeri dan stress yang dialami oleh pasien. Hal ini sejalan dengan Ayudianningsih \& Maliya, (2009) Teknik relaksasi membuat pasien dapat mengontrol diri ketika terjadi rasa tidak nyaman atau nyeri, stress fisik dan emosi pada nyeri.

Berdasarkan distribusi frekuensi pendidikan mengenai Pelaksanaan teknik relaksasi oleh perawat pada pasien adalah sebagian besar pendidikan responden Diploma sebanyak 10 perawat $(62,5 \%)$, dan pendidikan Sarjana yaitu sebanyak 6 responden $(37,5 \%)$. Dari pernyataan diatas dapat dilihat dari 16 perawat sebagian besar pada kelompok pendidikan D3. Pelaksanaan teknik relaksasi berdasarkan pendidikan perawat di ruang Topas RSU dr. Slamet Garut Tahun 2012,Pendidikan Diploma perawat yang melaksanakan 
teknik relaksasi sebanyak 4 orang atau $40 \%$ dan perawat yang tidak melaksanakan sebanyak 6 orang atau 60\%. Dan pendidikan Sarjana perawat yang melaksanakan sebanyak 4 orang atau $66,5 \%$, sedangkan perawat yang tidak melaksanakan sebanyak 2 orang atau 33,5\%. Hal ini terjadi dikarenakan pendidikan Diploma dalam pengalaman praktik lapangan lebih dominan dibandingkan dengan Sarjana yang lebih di fokuskan ke teori. Menurut teori Green, 2002 dalam Suharyat, Y. (2009) bahwa pendidikan merupakan faktor predisposisi seseorang untuk berprilaku,sehingga latar belakang pendidikan merupakan faktor yang mendasar dan memotivasi terhadap prilaku atau memberikan referensi pribadi dalam pengalaman belajar.

Hasil penelitian ini menunjukan responden yang berpendidikan Diploma sama besar yang melakukan teknik relaksasi dengan Sarjana, artinya pendidikan Sarjana dalam hal ini pengalaman praktik lapangan sama dengan pendidikan Diploma. Upaya yang harus di perhatikan pendidikan Diploma maupun pendidikan Sarjana bahwa pelaksanaan teknik relaksasi pada pasien pre maupun post operasi sangatlah penting dan harus diperhatikan karena teknik relaksasi dapat mengurangi intensitas nyeri dan stress yang dialami oleh pasien. Pelaksanaan teknik relaksasi berdasarkan jadwal dinas perawat di ruang Topas RSU dr. Slamet
Garut pada jadwal dinas pagi perawat yang melaksanakan teknik relaksasi sebanyak 7 orang atau $100 \%$ dan tidak ada perawat yang tidak melaksanakan teknik relaksasi,jadwal dinas siang perawat yang melaksanakan teknik relaksasi sebanyak 1 orang atau 20\% dan perawat yang tidak melaksanakan sebanyak 4 orang atau 80 $\%$,sedangkan yang dinas malam semua perawat tidak melaksanakan teknik relaksasi sebanyak 4 orang atau $100 \%$. Hal ini terjadi dikarenakan pada jdwal dinas pagi kepala ruangan maupun CI ikut hadir sehingga mempengaruhi perawat untuk melaksanakan teknik relaksasi dan pasiennya pun pada pagi hari mebutuhkan rileksasi agar nyeri yang diraskan berkurang sedangkan pada siang maupun malam disamping tidak ada kepala ruangan dan CI pasien nya pun kadang-kadang tidur sendiri di saat perawat sedang melaksanakan tindakan pun pasien sudah rileks sendiri bahkan ada yang tidur.

Menurut Aurora, N., \& Rahardja, R. (2010) jadwal dinas yaitu suatu jadwal yang mengatur siklus jaga dan petugas yang harus memberikan atau menunjang pelayanan dan tindakan keperawatan. Upaya yang diperhatikan agar perawat dapat melaksanakan teknik relaksasi yaitu dengan melakukan briping terlebih dahulu yang dipimpin oleh kepala ruangan dengan menyertakan semua perawat dari ke 3 dinas agar perawat dapat mengetahui dan melaksanakan teknik relaksasi terhadap 
pasien. Menurut Smeltzer dan Bare tahun 2002 dalam Wirya \& Sari (2013), teknik relaksasi dipercaya dapat menurunkan nyeri dengan merilekskan ketegangan otot yang menunjang nyeri. Relaksasi merupakan kebebasan mental dan fisik dari ketegangan dan stress, karena dapat mengubah persepsi kognitif dan motivasi afektif pasien.

Pelaksanaan teknik relaksasi berdasarkan jenis kelamin perawat di ruang Topas RSU dr. Slamet Garut, perawat yang berjenis kelamin laki-laki 7 orang yang melaksanakan atau 50\% dan perawat yang tidak melaksanakan sebanyak 7 orang atau $50 \%$,sedangkan perawat perempuan yang melaksanakan teknik relaksasi sebanyak 1 orang atau $50 \%$ dan perawat yang tidak melaksanakan teknik relaksasi sebanyak 1 orang atau 50\%. Menerut Wahyuningsih, Haryanti \& Subekti (2008) didalam kinerja perawat dalam melaksanakan tindakan keperawatan mungkin berbeda berkaitan dengan cirri fisik,karakter dan sifat yang berbeda pula, jenis kelamin adalah penggolongan responden yang terdiri dari laki-laki dan perempuan.

Hasil penelitian ini menunjukan bahwa, baik perawat yang berjenis kelamin laki-laki maupun perempuan ternyata tidak mempengaruhi pelaksanaan teknik relaksasi karena baik yang berjenis kelamin laki-laki maupun perempuan sama-sama seimbang dalam pelaksanaan teknik realaksasi yaitu $50 \%$ yang melaksanakan dan $50 \%$ lagi tidak melaksanakan teknik relaksasi. Upaya yang harus diperhatikan agar perawat dapat melaksanakan teknik relaksasi yaitu diberikan pengarahan oleh kepala ruangan dengan tidak memandang jenis kelamin perawat, baik yang laki-laki maupun perempuan harus melaksanakan teknik realaksasi terhadap pasien karena teknik ini sangat penting bagi kesembuhan pasien.

\section{KESIMPULAN DAN SARAN}

\section{Kesimpulan}

Penatalaksanaan gangguan rasa nyaman nyeri dengan teknik relaksasi pada perawat di Ruang Topas RSU dr. Slamet Garut yang melaksanakan teknik relaksasi yaitu : Perawat yang Pendidikan Diploma lebih banyak tidak melaksanakan teknik relaksasi dibanding yang pendidikan Sarjana, Jadwal dinas pagi perawat, lebih banyak perawat yang melaksanakan teknik relaksasi dari pada dinas yang lain yaitu, dan Jenis kelamin perawat, perawat yang berjenis kelamin laki-laki lebih banyakn yang melaksanakan teknik relaksasi dibanding perempuan.

\section{Saran}

Diharapkan dapat menambah Motivasi atau perhatian dari berbagai pihak khususnya perawat dalam melaksanakan teknik relaksasi pada semua pasien baik itu yang pre maupun post operasi untuk menurunkan tingkat kecemasan dan intensitas nyeri yang dialami oleh pasien. 


\begin{tabular}{l} 
Upaya yang harus dilakukan \\
perawat, dimana tindakan non \\
farmakologis yaitu teknik relaksasi \\
mendapat citra suatu tugas yang menarik \\
atau membosankan, kreatif atau membuat \\
tak bersemangat, mudah atau sulit, \\
menantang atau tidak. Apabila teknik \\
relaksasi mempunyai citra tindakan yang \\
menarik atau menantang maka akan \\
meningkatkan motivasi perawat dalam \\
melaksanakan teknik relaksasi. \\
\hline 1, 2 Fakultas Keperawatan Universitas \\
Padjadjaran Kampus Garut
\end{tabular}

\section{DAFTAR PUSTAKA}

Arikunto, Suharsimi. (2010). Prosedur Penelitian Suatu Pendekatan Praktik. Edisi Revisi. Jakarta: PT Rineka Cipta.

Aurora, N., \& RAHARDJA, R. (2010). Penerapan Balanced Scorecard Sebagai Tolak Ukur Pengukuran Kinerja (Studi Kasus Pada RSUD Tugurejo Semarang) (Doctoral dissertation, UNIVERSITAS DIPONEGORO).

Ayudianningsih, N. G., \& Maliya, A. (2009). pengaruh teknik relaksasi nafas dalam terhadap penurunan tingkat nyeri pada pasien pasca operasi fraktur femur di rumah sakit karima utama Surakarta.

Brunner \& Suddarth. (2001). Buku Ajar Keperawatan Medikal-Bedah. Jakarta: EGC
Hidayat. (2007). Pengantar Konsep Dasar Keperawatan. Jakarta: Salemba medika.

Notoatmodjo, Soekidjo. (2010). Metodologi Penelitian Kesehatan. Edisi Revisi Jakarta : PT Rineka Cipta

Pinandita, I., Purwanti, E., \& Utoyo, B. (2012). Pengaruh teknik relaksasi genggam jari terhadap penurunan intensitas nyeri pada pasien post operasi laparatomi. Jurnal Ilmiah Kesehatan Keperawatan, 8(1).

Setiadi. (2007). Riset Keperawatan. Yogyakarta: Graha ilmu.

Suharyat, Y. (2009). Hubungan antara sikap, minat dan perilaku manusia. Jurnal Region, 1(3), 1-19.

Wahyuningsih, S., Haryanti, F., \& Subekti, H. (2008). Tingkat Perkembangan Bahasa dan Sosial Kemandirian Anak usia Prasekolah pada TK FullDay dan TK Half-Day. Jurnal Ilmu Keperawatan, 3(1), 50-56.

Wirya, I., \& Sari, M. D. (2013). Pengaruh pemberian masase punggung dan teknik relaksasi nafas dalam terhadap penurunan intensitas nyeri pada pasien post appendiktomi di zaal C RS HKBP Balige tahun 2011. Jurnal Keperawatan HKBP Balige, 1(1).

Zees, R. F. (2012). Pengaruh Tehnik Relaksasi Terhadap Respon Adaptasi Nyeri Pada Pasien Apendektomi Di Ruang G2 Lantai Ii Kelas Iii Blud Rsu Prof. Dr. H. Aloei Saboe KOTA GORONTALO. Jurnal Health and Sport, 5(03). 